\title{
Captures au piège Agraphid de cicadelles vectrices de virus persistants nuisibles aux poacées *
}

\author{
JP Moreau \\ Unité de zoologie, Inra, F-78026 Versailles, France \\ (Reçu le 20 mai 1995 ; accepté le 4 juillet 1995)
}

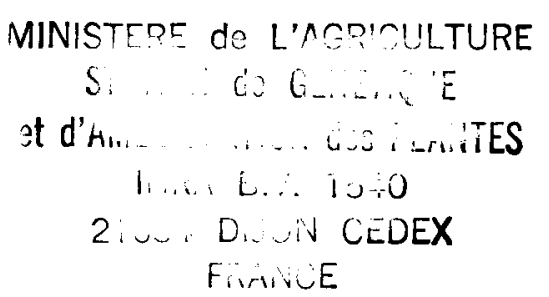

\begin{abstract}
Résumé - Les pullulations de pucerons des céréales (Sitobion avenae F) de 1973 à 1975 en Europe de l'Ouest ont poussé à l'installation d'un réseau de pièges à succion (Agraphid), à l'instar du réseau britannique. Depuis, si les aphides ont pris de plus en plus de place dans les préoccupations des agriculteurs, c'est surtout parce qu'ils transportent et inoculent des virus dommageables à de nombreuses cultures. En dehors des pucerons, on trouve sur poacées des cicadelles, vectrices elles aussi de viroses. Comme les formes ailées des pucerons, les cicadelles adultes font partie du plancton aérien, et dans le piège de l'Inra-Versailles, on a noté les captures de certaines espèces majeures, dont le delphacidé Javesella pellucida Fall et le cicadellidé Psammotettix alienus Fall, vecteur du virus du nanisme du blé qui a causé récemment d'importants dégâts en France. La présence de ces cicadelles dans les prises du réseau de pièges peut permettre une meilleure appréciation des risques viraux dans les semis d'automne des céréales.
\end{abstract}

Javesella pellucida / Psammotettix alienus / cicadelle / piège à succion / virus persistant / poacée /

Summary - Catching vectors of Poaceae viruses Javesella pellucida and Psammotettix alienus in suction traps. As a large number of cereal aphids (Sitobion avenae Fabr) were found between 1973 and 1975, a network of suction traps (Agraphid) was constructed in western Europe to survey cereal aphids, following the example of the network in Britain. Farmers have since paid more attention to the damage caused by aphids, which carry and transmit viruses to cultivated plants. Besides aphids, leaf- and plant-hoppers are also found as virus vectors on Poaceae. Adult leaf- and plant-hoppers made up part of the winged aphid population caught by the suction trap in Versailles (INRA). The major species caught were Javesella pellucida and Psammotettix alienus from 1989 to 1994; the latter is an important vector of wheat dwarf virus (WDV). Since WDV has caused economically important losses of cereal in France during recent years, the capture of $\mathrm{P}$ alienus may be used to estimate the risk of primary infection of WDV in autumn-sown cereals.

Javesella pellucida / Psammotettix alienus / virus vectors / suction trap / wheat dwarf virus / Poaceae

\section{INTRODUCTION}

Depuis longtemps, le vol des insectes à diverses hauteurs a intéressé les entomologistes. Berland (1935) a capturé des jassides près de Paris entre 1000 et $1200 \mathrm{~m}$ d'altitude et Glick (1939) a montré que les homoptères, pucerons et surtout cicadelles, se répartissaient en gradient dégressif de 60 à $1500 \mathrm{~m}$. Lors de leurs vols migratoires, des cicadelles vectrices sont capables de franchir de grandes distances, comme Circulifer tenellus Bak de la Californie à l'Utah, ainsi que

\footnotetext{
* Communication presented to the Conference on Virus Diseases of the Poaceae - 1994. See agronomie vol 15, n 7-8.
} 
I'ont montré Douglass et Cook (1954). Johnson (1969) a rassemblé ces observations, avec beaucoup d'autres, dans son ouvrage "Migration and Dispersal of Insects by Flight".

Le Royaume-Uni a été le premier à installer un réseau de pièges à succion (RIS) destiné à étudier les vols de pucerons (Bent et al, 1987). Après une étude exploratoire, il a été décidé de placer le niveau d'aspiration de ces tours à $12,33 \mathrm{~m}$ (40 pieds), hauteur qui s'était révélée comme la plus efficace en moyenne pour la capture de différentes espèces. Elle est de plus considérée comme suffisante pour rendre minoritaires les captures "de proximité", à condition bien évidemment que le piège soit disposé dans un emplacement dégagé. Bien que les paramètres climatiques de chaque pays conditionnent l'abondance relative des pucerons en déplacement et la hauteur moyenne de leur vol, la France puis d'autres pays de l'Europe de I'Ouest ont adopté a priori la même hauteur pour les pièges qu'ils ont installés à partir de 1978, après les pullulations de pucerons des céréales (Sitobion avenae) de 1968, 1974 et surtout 1975.

À bonne hauteur pour les principaux pucerons, l'aspiration à 40 pieds est peut-être insuffisante pour des cicadelles en migration. Cependant, à l'apparition du nanisme du blé en France, il nous a paru utile de trier les auchénorrhynques capturés au piège Agraphid situé depuis 1984 à La Verrière (78), à $14 \mathrm{~km}$ au sud-ouest de Versailles. Quand le piège d'Auxerre (89) a été installé, les captures de Psammotettix spp y ont été notées, ainsi qu'à celui d'Orléans (45), tous deux plus proches des dégâts de nanisme (Moreau et al, 1993).

Parmi les virus transmis aux poacées selon le mode persistant par des auchénorrhynques, on peut distinguer des non-multipliants, comme le géminivirus du nanisme du blé (wheat dwarf virus), transmis par le cicadellidé Psammotettix alienus et des multipliants, dont un certain nombre sont présents en Europe. L'un de ces derniers, le MRDV (maize rough dwarf virus), est depuis peu à l'origine de dégâts sur les cultures de maïs du sud-ouest de la France. Les responsables de la transmission de virus multipliants, (réovirus, ténuivirus, rhabdovirus ou marafivirus) sont uniquement des delphacidés (tableau I).

\section{RÉSULTATS}

Trois espèces de cicadelles parmi celles inféodées aux poacées représentent la presque totalité des captures d'auchénorrhynques pour les six dernières années : une espèce non vectrice, Zyginidia scutellaris HS (803 exemplaires) et deux espèces vectrices, $P$ alienus (parmi 48 Psammotettix spp) et $J$ pellucida (1 004 individus). L'absence de $L$ striatellus est remarquable. Ce delphacide est cependant présent dans la région puisqu'on le capture au filet fauchoir (Della Giustina, com pers).

Comme le géminivirus du nanisme du blé est non-multipliant, ce sont surtout les effectifs migrants des insectes à partir des réservoirs

Tableau I.

\begin{tabular}{|c|c|c|}
\hline Type de virus & Maladie & Vecteur \\
\hline \multicolumn{3}{|l|}{ Circulant } \\
\hline Geminivirus & Nanisme du blé & $P$ alienus \\
\hline \multicolumn{3}{|l|}{ Multipliant } \\
\hline Reovirus (Fijivirus) & $\begin{array}{l}\text { Nanisme rugueux du maïs a } \\
\text { Maladie du tallage des céréales } \\
\text { Nanisme stérile de l'avoine }\end{array}$ & $\begin{array}{l}\text { L striatellus } \\
J \text { pellucida } \\
\text { id }\end{array}$ \\
\hline Tenuiviris & Mosaïque striée du blé & id \\
\hline Rhabdovirus & Mosaïque striée de l'orge a & $L$ striatellus \\
\hline Marafivirus & Nanisme bleu de l'avoine & $J$ pellucida \\
\hline
\end{tabular}

\footnotetext{
a Virus caractérisé en France.
} 
(resemis de blé) qui conditionnent l'inoculum de départ. Le vecteur $P$ alienus est régulièrement présent en faible nombre parmi les captures du piège de l'Inra-Versailles (la plupart des individus mâles des Psammotettix spp piégés sont des $P$ alienus, et quelques-uns d'entre eux des $P$ confinis). Depuis les importants dégâts dus au nanisme enregistrés dans les régions Centre et Bourgogne vers 1989, les captures du vecteur aux pièges à succion ont eu tendance à diminuer. Les tours du réseau n'ont capturé au plus qu'une vingtaine d'individus de $P$ sammotettix spp en 1993 et 1994, alors que la tour d'Auxerre en avait pris davantage pour sa première année de fonctionnement. La figure 1, qui compare les captures d'automne à Versailles et à Auxerre, montre un pic correspondant pour l'année 1991 en Bourgogne, où les dégâts de la virose ont été encore notables. II conviendrait de rester vigilant à l'avenir pour prévenir le risque automnal pour les blés. Les effectifs de $P$ alienus capturés fin septembre et début octobre dans le réseau Agraphid seront toujours un précieux renseignement pour les services de la protection des végétaux.

Les virus "multipliants" sont ceux dont le titre augmente dans le vecteur après son repas contaminant. De plus, ce type de virus peut passer de la mère à l'œuf. Leur épidémiologie est cependant soumise à l'existence de réservoirs végétaux, comme l'a bien montré Nuorteva (1954). Jusqu'à présent soit la faiblesse des effectifs des insectes aux moments inopportuns, soit le très bas niveau d'inoculum viral, soit des tolérances-résistances peu élucidées du matériel végétal, soit les interventions insecticides contre les pucerons n'ont pas permis l'expression de dommages caractérisés dans les grandes zones céréalières françaises. Rappelons que seul le MRDV, transmis au maïs par $L$ striatellus, a été récemment la cause de dégâts localisés dans le sud-ouest.
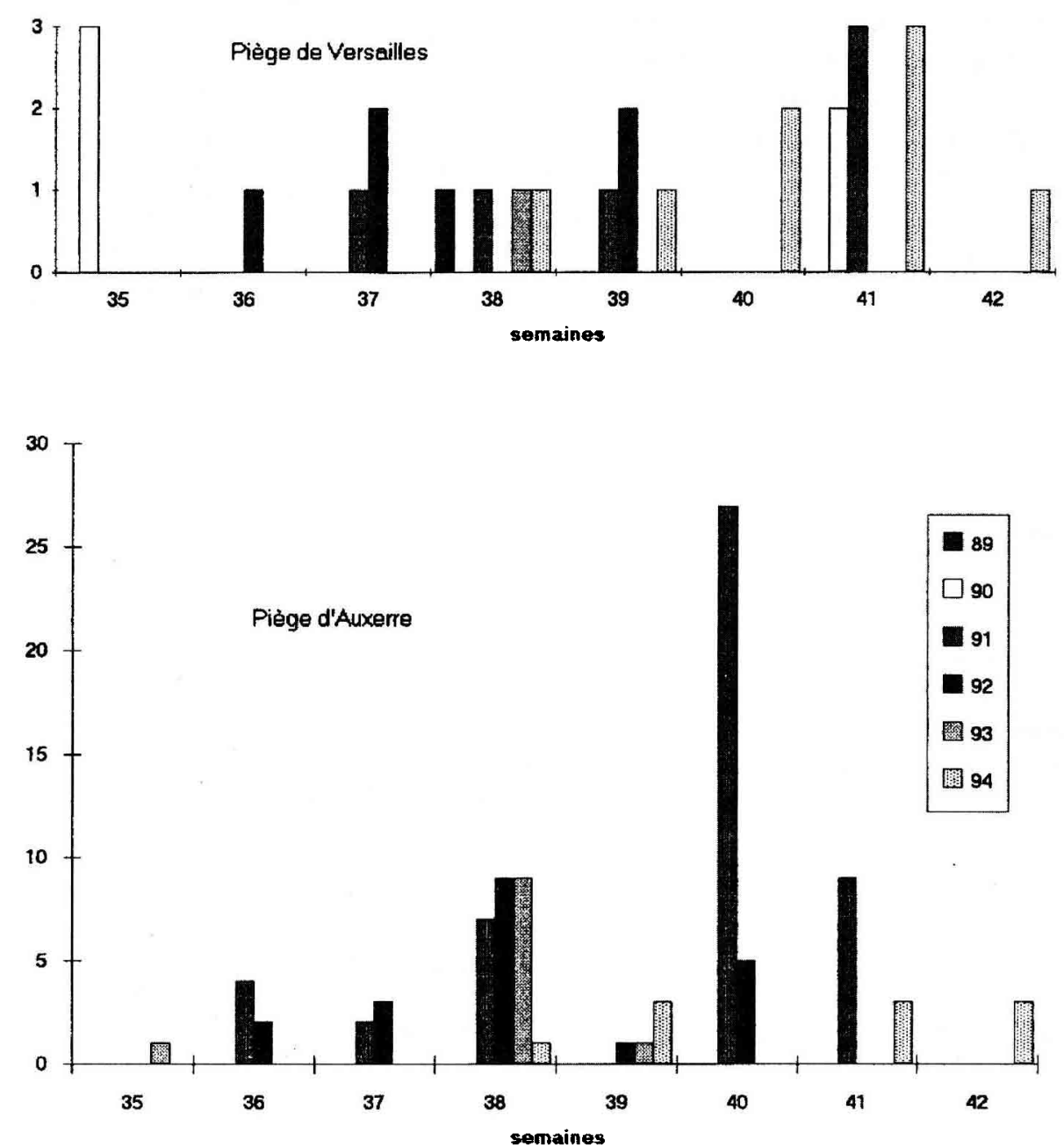

Fig 1. Captures hebdomadaires de Psammotettix spp à l'automne, en île-de-France et en Bourgogne. 

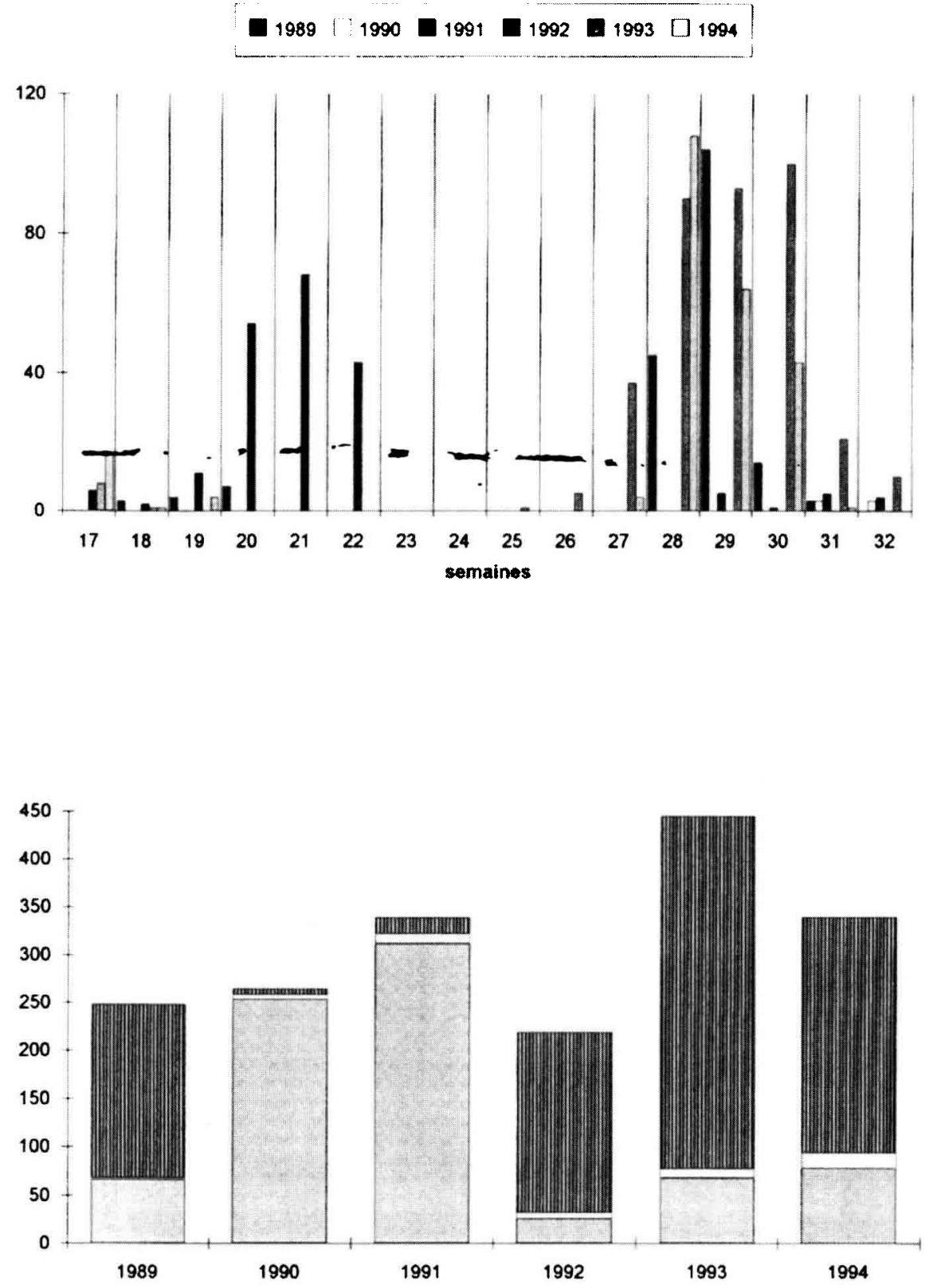

Fig 2. Captures hebdomadaires de $J$ pellucida au piège Agraphid de Versailles de 1989 à 1994.
Fig 3. Captures annuelles de cicadelles au piège Agraphid de Versailles de 1989 à 1994. 血 Javesella pellucida; O Psammotettix sp ; Zyginidia scutellaris.
Il est intéressant de constater que le piège à succion de I'Inra-Versailles n'a capturé $J$ pellucida qu'exceptionnellement début septembre, et jamais en octobre (phénomène vérifié depuis 1984). Son principal pic de captures se situe au printemps, comme en 1992, ou plutôt en été, comme 1989, 1993 et 1994 (fig 2). Du point de vue des captures annuelles de cicadelles, $J$ pellucida a souvent été bien représentée. En particulier elle a été fortement majoritaire au cours des 3 dernières années. En revanche 1990 et 1991, années à fort déficit pluviométrique, ont vu de faibles captures du delphacide, alors que la petite cicadelle du maïs, $Z$ scutellaris, était abondante (fig 3 ).
II semblerait donc que, jusqu'à présent, les céréales d'hiver n'aient pu être visitées aux stades jeunes par les delphacides, au moins dans les conditions de notre région. II n'en reste pas moins que ce type de risque, faible pour l'île-de-France, mérite d'être pris en compte dans les autres régions, pour savoir si la présence des nouvelles jachères dans le cadre de la Pac peut modifier la multiplication et les déplacements de populations virulifères. De même qu'il la fait récemment pour $P$ alienus, le réseau Agraphid serait capable de contribuer à la surveillance des delphacides nuisibles, $L$ striatellus et $J$ pellucida. 


\section{RÉFÉRENCES}

Bent CA, Carter N, Harrington R, Tatchell GM, Taylor MS, Woiwod IP (1987) The present status and future developments in the Rothamsted Insect Survey. In : Aphid Migration and Forecasting "Euraphid" Systems in European Community Countries (R Cavalloro, ed), CEC Publ, 201-207

Berland L (1935) Premiers résultats de mes recherches en avion sur la faune et la flore atmosphérique. Ann Soc Ent Fr 104, 73-96
Douglass JR, Cook WC (1954) The beet leafhopper. Circ US Dep Agric 942, 21 pp

Glick PA (1939) The distribution of insects, spiders and mites in the air. Tech Bull US Dep Agric 373, 150 pp

Johnson CG (1969) Migration and Dispersal of Insects by Flight. Methuen and Co Ltd, $763 \mathrm{p}$

Moreau JP, Cadiou O, Serain M, Lochon S (1993) Les pièges du réseau Agraphid capturent aussi des cicadelles. Persp Agric 173, 27-8

Nuoterva P (1962) Studies on the causes of the phytopathogenicity of Calligypona pellucida (F) (Hom, Anaeopidae). Ann Zool Soc "Vanamo"23, 4-58 